\title{
Impact of School Enrolment Size on Student's Achievements
}

\section{Muhammad Hafeez*1), Qaiser Abbas Kazmi2), Fatima Tahira3), Muhammad Zahid ${ }^{4)}$, Hussain Sajad5), Ahmad Azra Yasmeen'), Jamshaid Iqbal7) \& Muhammad Ishaq Saqi8)}

1). Department of Science education Allama Iqbal Open University, Islamabad. 2). Regional Director, Allama Iqbal Open University, Islamabad, D. G. Khan Campus

3). Department of Science education Allama Iqbal Open University, Islamabad.

4). Government Boys College, Block no. 17, Dera Ghazi Khan, Punjab, Pakistan. 5). Subject Specialist, School Education Department, Dera Ghazi Khan, Punjab, Pakistan. 6). Quaid-E-Azam Academy for Educational Development, Dera Ghazi Khan, Punjab, Pakistan. 7). Assistant Education Officer, School Education Department, Dera Ghazi Khan, Punjab, Pakistan. 8). Senior Subject Specialist, School Education Department, Dera Ghazi Khan.

Received: June 2020; Accepted: August 2020; Published: Agustus 2020

*Coresponding Email: mh9589041@gmail.com

\begin{abstract}
Education is a basic need of humanity and key element for the development of a nation. The population is increasing day by day and the main problem of education particularly in primary education is the increasing of number of students in the schools. So, the enrolment size of schools is increasing consistently. The effect of school enrolment size on the student's achievement has been a major factor for the failure of the education system especially primary education. The purpose of this research is to discover the possible relations between the school enrolment size and student's achievements. The data of four primary schools namely GPS Gaggu, GPS Samina, GPS Tagiani and GPS Yaroo has been selected to check the effect of school enrolment size on the student's achievements. The results of the study indicate that as the enrolment size increased in the school, the achievements of the student's decreased and vice versa.
\end{abstract}

Key Words: Enrolment size, Achievement, School, D. G. Khan

How to Cite: Hafeez, M., Kazmi, Q.A., Tahira, F., Zahid, M., Sajad, H., Yasmeen, A.A., Iqbal, J. \& Saqi, M.I. (2020). Impact of School Enrolment Size on Student's Achievements. Journal of Education, Humaniora and Social Sciences (JEHSS). 3 (1): 26-30. 


\section{INTRODUCTION}

In light of rapidly increasing enrollment in primary schools across the nation, administrators are under fire concerning the issue of growing class size and the potential diminishment of academic standards. In assessing the possible effect of class size on achievement, the issue of a good measure of academic achievement has been called into question. (Toth and Montagna, 2002) stated that the influence of class size on achievement depends upon the measure of achievement and that results of studies surveyed conclude that when measures of knowledge are used, the large class method is as effective as the small-class methods. However, when measures of transfer of knowledge to new situations, retention of information, problem solving, critical thinking, and attitude change or motivation, it is very importantant to keep the enrollment size small. The objectives of this research are (i) To study the effect of annually increasing school enrolment on the student's achievements (ii) To compare the student's achievements of lower enrolled schools and higher enrolled schools.

The debate about the effects of school size has a long history. Larger-school advocates contend that they allow for more varied curriculum and extra-curricular activities. Smaller school promoters argue that large schools allow students to fall through the cracks, whereas small schools promote more personal attention for students (Bullard, 2011). School size is one potential measure of school quality over which policymakers have some control (Gershenson \& Langbein, 2015). Numerous studies, reviewed by (Andrews et al., 2002; Cotton, 1996) and Leithwood and Jantzi, 2009) have investigated the relationship between school size and academic achievement. (Lee, et al., 2000) in a qualitative study of small and large schools, documented that students in small schools reported generally higher levels of support and caring among the members of their school communities. New investigation designates that smaller schools have greater student success, better attendance and contribution in school actions confident interactions between students, instructors and parents. More current studies suggest that small schools are well than large ones, particularly for students with lesser socio-economic position. There are countless references, conference papers and journal articles illuminating the merits of small schools (Schneider, 2002). (Akerlof \&Kranton, 2002) argued that students in small schools benefit by being better able to identify with the school and with each other. Class size is viewed as an enabler of more effective instruction that can improve student learning (Konstantopoulos \& Sun, 2014).

(Blatchford, et al., 2007) have reported that in smaller classes there were more frequent interactions between students and teachers with respect to knowledge building and learning activities. One substitute to generating small schools is the school within a school where larger schools are sectioned into smaller elements. However, as this is a comparatively new inventiveness, the work is less decisive than the influences in favour of school size. The ideal size of the school is not just about the number of students' presence, and there are many other issues that distress the superiority of education in schools. However, most revisions propose that the optimal size is somewhere between large and small. This proposes that medium 'sized schools are the best with registrations between 200 and 500 for primary schools. Medium sized schools can deliver the best of both words (Richard, 2005).

\section{MATERIALS AND METHODS}

This research is comparative study of four primary schools to see the effect of school enrollment size on the student's achievements. The data is collected from the previous enrolment size and results of the schools. The four year's data from 2015 to 2018 of each school has been used in this research. The years, school enrolment and student's achievements selected for this research is shown in Tables 1, 2, 3 and 4.

Table 1: Enrolment and student's achievements of GPS Gaggu

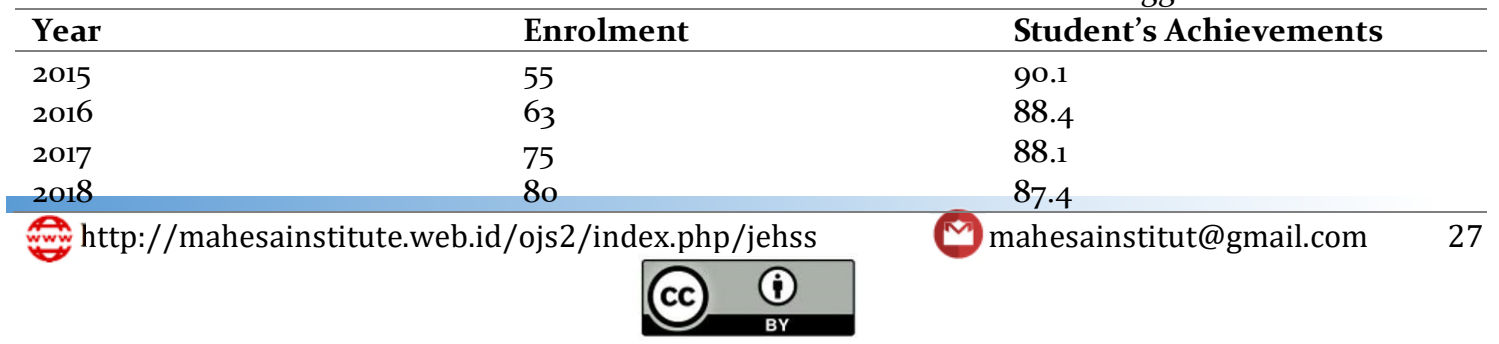

This work is licensed under a Creative Commons Attribution 4.0 
Table 2: Enrolment and student's achievements of GPS Samina

\begin{tabular}{lll}
\hline Year & Enrolment & Student's Achievements \\
\hline 2015 & 75 & 89.2 \\
2016 & 83 & 88.5 \\
2017 & 95 & 88.1 \\
2018 & 103 & 87.6 \\
\hline
\end{tabular}

Table 3: Enrolment and student's achievements of GPS Tagiani

\begin{tabular}{lll}
\hline Year & Enrolment & Student's Achievements \\
\hline 2015 & 55 & 87.7 \\
2016 & 67 & 86.8 \\
2017 & 82 & 86.1 \\
2018 & 89 & 85.8 \\
\hline
\end{tabular}

Table 4: Enrolment and student's achievements of GPS Yaroo

\begin{tabular}{lll}
\hline Year & Enrolment & Student's achievements \\
\hline 2015 & 61 & 88.2 \\
2016 & 72 & 87.5 \\
2017 & 85 & 87.1 \\
2018 & 93 & 86.2 \\
\hline
\end{tabular}

\section{Findings}

The relationship between enrolment and student's achievements of GPS Gaggu is shown in figure 1. The figure shows that when the enrolment is less then student's achievements is greater and when the enrolment is increased then the student's achievements are decreased.

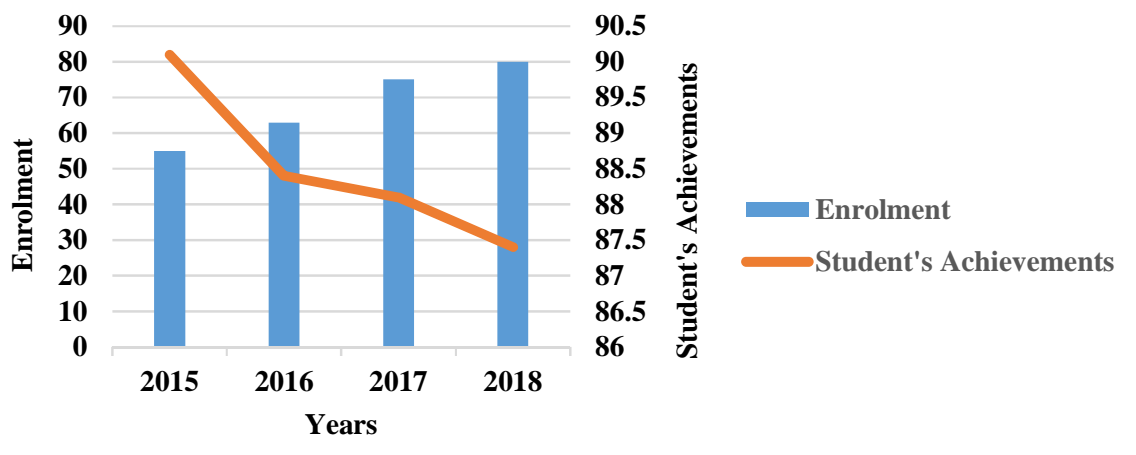

Figure. 1: Graph between Enrolment and Student's Achievements of GPS Gaggu

The relationship between enrolment and student's achievements of GPS Samina is shown in figure 2. The figure shows that when the enrolment is less then student's achievements is greater and when the enrolment is increased then the student's achievements are decreased. 
Vol 3, No. 1, Agustus 2018: 26-30

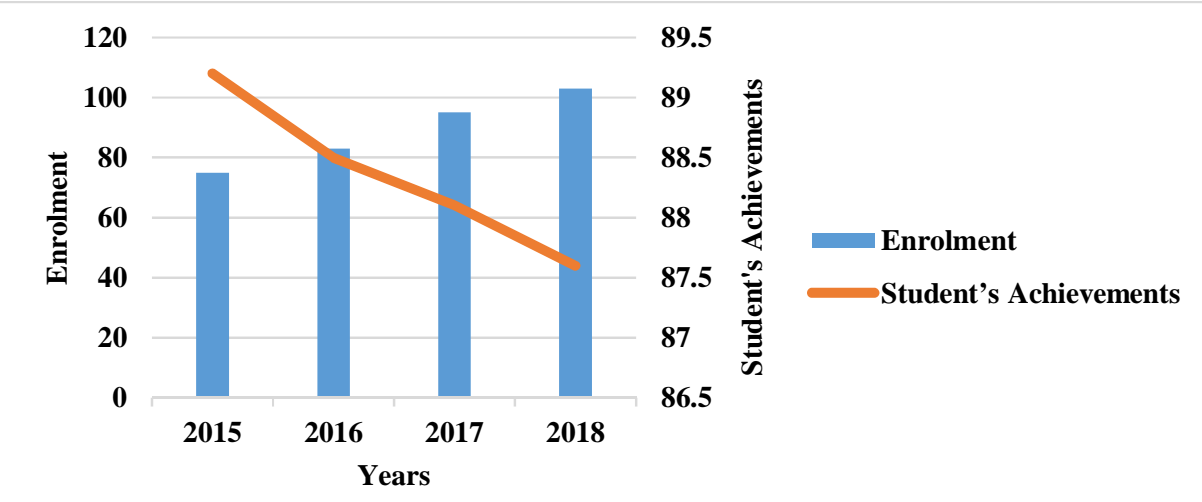

Figure 2: Graph between Enrolment and Students Achievements of GPS Samina

The relationship between enrolment and student's achievements of GPS Tagiani is shown in figure 3. The figure shows that when the enrolment is less then student's achievements is greater and when the enrolment is increased then the student's achievements are decreased.

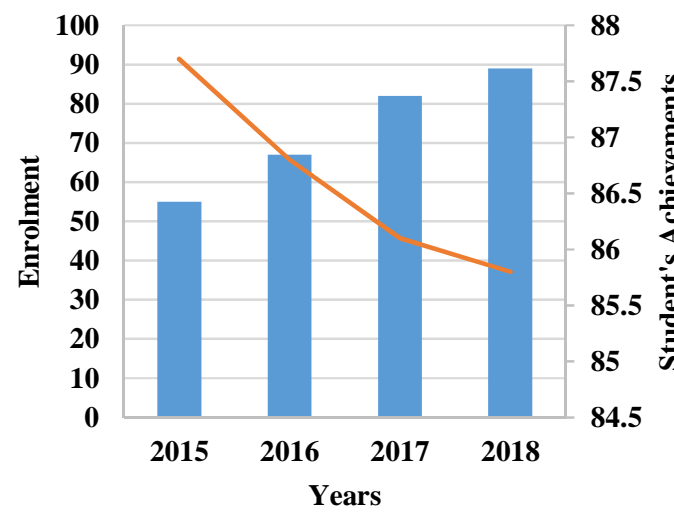

Enrolment

Student's Achievements

Figure 3: Graph between Enrolment and Student's Achievements of GPS Tagiani

The relationship between enrolment and student's achievements of GPS Yaroo is shown in figure 4. The figure shows that when the enrolment is less then student's achievements is greater and when the enrolment is increased then the student's achievements are decreased.

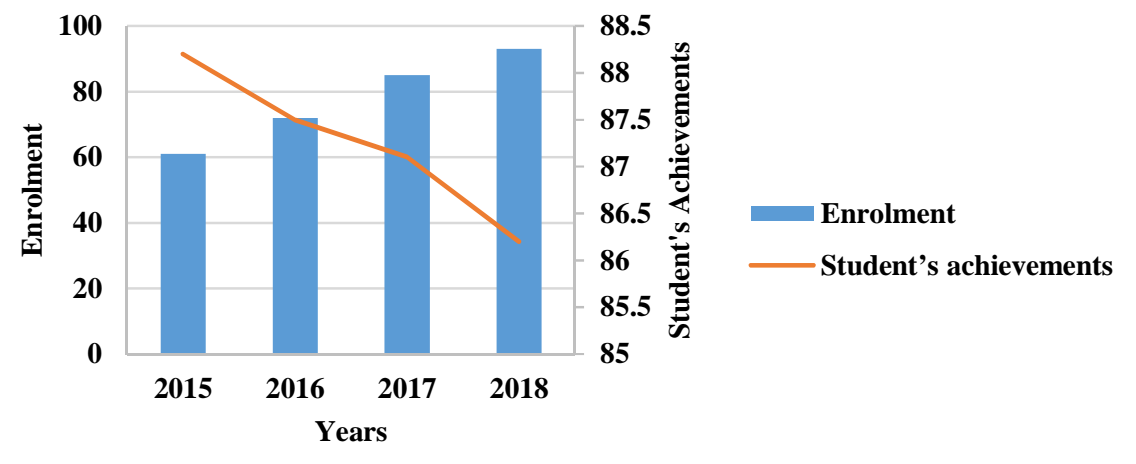

Figure 4: Graph between Enrolment and Student's Achievements of GPS Yaroo

\section{CONCLUSION}

The aim of this quantitative research is to analyses the effect school enrolment on student's achievements. The results show that when the new student's enrolment is increased then student's academic achievements is reduced. In this way student enrolment has directly effect on the

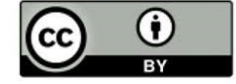

This work is licensed under a Creative Commons Attribution 4. 
student's achievement. This effect of new enrolment student has the linear relation with the student's achievements. So it is recommended that (i) To decrease the number of student in the class for the better student achievement. (ii) To increase the number of teachers to enhance the student achievement. (iii) To increase the number of school for the excellent student achievement.

\section{REFERENCES}

Toth, L. S., \& Montagna, L. G. (2002). Class size and achievement in higher education: a summary of current research. College Student Journal, vol. 36(2), pp. 253-261.

Bullard, H. C. (2011). The effects of school enrollment size on student achievement (Doctoral dissertation, Georgetown University). Chicago

Gershenson, S., \& Langbein, L. (2015). The effect of primary school size on academic achievement. Educational Evaluation and Policy Analysis, 37(1_suppl), 135S-155S.

Andrews, M., Duncombe, W., \& Yinger, J. (2002). Revisiting economies of size in American education: Are we any closer to a consensus? Economics of Education Review, 21, 245-262.

Cotton, K. (1996). School size, school climate and student performance. Portland, OR: Northwest Regional Educational Laboratory.

Leithwood, K., \& Jantzi, D. (2009). A review of empirical evidence about school size effects: A policy perspective. Review of Educational Research, 79, 464-490.

Lee, Valerie E., Becky A. Smerdon, Corinne Alfred-Liro, and Shelly L. Brown. 2000. "Inside Large and Small High Schools: Curriculum and Social Relations." Educational Evaluation and Policy Analysis 22:14771.

Schneider, Mark (2002), Do School Facilities Affect Academic Outcomes? National Clearinghouse for Educational Facilities.

Akerlof, G. A., \& Kranton, R. E. (2002). Identity and schooling: Some lessons for the economics of education. Journal of Economic Literature, 40, 1167-1201.

Konstantopoulos, S., \& Sun, M. (2014). Are teacher effects larger in small classes? School Effectiveness and School Improvement, 25, 312-328.

Blatchford, P., Russell, A., Bassett, P., Brown, P., \& Martin, C. (2007). The effect of class size on the teaching of pupils aged 7-11 years. School Effectiveness and School Improvement, 18, 147-172.

Harker, Richard (2005), School size and student attainments: Some New Zealand data CIES (West) Conference, Vancouver, Sept 29 - Oct 1, 2005 College of Education Massey University. 